\title{
openheart Premedication to reduce anxiety in patients undergoing coronary angiography and percutaneous coronary intervention
}

\author{
Wieneke Vlastra, ${ }^{1}$ Ronak Delewi, ${ }^{1}$ Wim J Rohling, ${ }^{1}$ Tineke C Wagenaar, ${ }^{1}$ \\ Alexander Hirsch, ${ }^{1}$ Martin G Meesterman, ${ }^{1}$ Marije M Vis, ${ }^{1}$ \\ Joanna J Wykrzykowska, ${ }^{1}$ Karel T Koch, ${ }^{1}$ Robbert $\mathrm{J}$ de Winter, ${ }^{1}$ Jan Baan Jr, ${ }^{1}$ \\ Jan J Piek, ${ }^{1}$ Mirjam A G Sprangers, ${ }^{2}$ José P S Henriques ${ }^{1}$
}

To cite: Vlastra W, Delewi R, Rohling WJ, et al. Premedication to reduce anxiety in patients undergoing coronary angiography and percutaneous coronary intervention. Open Heart 2018;5:e000833. doi:10.1136/

openhrt-2018-000833

Received 11 April 2018

Revised 9 July 2018

Accepted 22 August 2018

Check for updates

(c) Author(s) (or their employer(s)) 2018. Re-use permitted under CC BY-NC. No commercial re-use. See rights and permissions. Published by BMJ.

${ }^{1}$ Heart Center, Department of Clinical and Experimental Cardiology, Amsterdam UMC, University of Amsterdam, Amsterdam Cardiovascular Sciences, Amsterdam, The Netherlands

${ }^{2}$ Department of Medical Psychology, Amsterdam UMC, University of Amsterdam, Amsterdam, The Netherlands

Correspondence to Dr Wieneke Vlastra; w.vlastra@ amc.uva.nl

\section{ABSTRACT}

Aims In this study, we examined the effects of the routinely administration of benzodiazepines on reducing periprocedural anxiety versus no premedication. Methods In this open label study, we enrolled 1683 patients undergoing diagnostic coronary angiograms (CAG) or percutaneous coronary interventions (PCI). Randomisation was simulated by systematically allocating patients in monthly rotational periods to lorazepam $1 \mathrm{mg} /$ sl, oxazepam $10 \mathrm{mg} / \mathrm{po}$, diazepam 5 mg/po, midazolam $7.5 \mathrm{mg} / \mathrm{po}$ or no premedication. Anxiety was measured at four different time points using the one-item Visual Analogue Scale for Anxiety (VAS score) ranging from 0 to 10 . The primary outcome was the difference in anxiety reduction ( $\triangle \mathrm{VAS}$, preprocedure to postprocedure), between the different premedication strategies versus no premedication.

Results Anxiety reduction was larger in patients premedicated with lorazepam $(\triangle \mathrm{VAS}=-2.0, \mathrm{SE}=1.6$, $\mathrm{P}=0.007)$ or diazepam $(\triangle \mathrm{VAS}=-2.0, \mathrm{SE}=1.5, \mathrm{p}=0.003)$ compared with patients without any premedication $(\triangle \mathrm{VAS}=-1.4, \mathrm{SE}=1.2)$. The use of midazolam or oxazepam did not lead to a significant reduction in anxiety compared with patients who did not receive premedication. Additionally, a high number of patients treated with midazolam ( $\mathrm{N}=39,19.8 \%)$ developed side effects. Conclusions In this study, the use of lorazepam or diazepam was associated with a significant, but modest anxiety reduction in patients undergoing CAG or PCl. This study does not support the standard use of oxazepam or midazolam as premedication to reduce anxiety.

\section{INTRODUCTION}

Anxiety is common among patients with coronary artery disease (CAD). ${ }^{1}$ Coronary angiograms (CAG) and percutaneous coronary interventions (PCI) are frequently performed diagnostic and therapeutic procedures with a relatively low risk. Nevertheless, many patients experience high levels of periprocedural anxiety, with reported
Key questions

What is already known about this subject?

- Anxiety during interventional procedures in the catheterisation laboratory is common and associated with reduced patient comfort as well as worse cardiovascular outcomes.

What does this study add?

- Currently, various benzodiazepines are used according to empirical experience. This study showed that the use of either lorazepam or diazepam prior to an interventional procedure had a positive, yet modest effect on anxiety levels. On contrary, both oxazepam and midazolam did not positively influence anxiety levels.

How might this impact on clinical practice?

- This study supports the standard administration of lorazepam or diazepam before coronary angiograms or percutaneous coronary interventions.

prevalence rates varying from $24 \%$ to $72 \% .^{2-5}$ High levels of anxiety preprocedure are associated with high levels of anxiety immediately after the procedure and likewise at discharge ${ }^{67}$ Accordingly, the preprocedural phase may be the most logical point for intervention, especially in patients (or subgroups) susceptible to higher levels of anxiety.

Little is known regarding the anxiolytic effect of procedural. ${ }^{589}$ Traditionally, different types of benzodiazepines are administered before the start of a CAG or PCI. ${ }^{10} 11$ Benzodiazepines increase the effect of the natural neurotransmitter gamma-aminobutyric acid at the receptor site in the brain, which initiates a reduction of neuron excitability with consequently anxiolytic, sedative and amnesic effects. ${ }^{12}$ However, there are scarce data supporting the use of benzodiazepines as anxiolytic agents for patients 
undergoing CAG or PCI. Correspondingly, there are no guidelines providing aid in selecting pharmacological strategies to reduce procedural anxiety. Consequently, the daily selection of anxiolytic premedication is currently not evidence-based but dependent on the operator's personal preference. Accordingly, in the current study, we determined the effects of the benzodiazepines lorazepam $1 \mathrm{mg} / \mathrm{sl}$, oxazepam $10 \mathrm{mg} / \mathrm{os}$, diazepam $5 \mathrm{mg}$ / os and midazolam $7.5 \mathrm{mg} / \mathrm{os}$ compared with no premedication on reducing anxiety levels in patients undergoing CAG or PCI.

\section{METHODS}

\section{Study overview}

The current study was conducted between April 2010 and February 2011 at the Academic Medical Center (AMC). The AMC is a high-volume tertiary cardiac care centre located in Amsterdam, the Netherlands. Procedural decisions, including device selection, were made at the discretion of the operator. The study protocol was approved by our local Institutional Review Board. Informed consent was waived since allocation to no premedication or one of the various benzodiazepines is considered common practice.

\section{Participants}

All patients undergoing a CAG or PCI were eligible to participate in the study. Patients who were unconscious or had insufficient proficiency of the Dutch language, preventing verbal or written assessment of anxiety, were excluded from the study. Moreover, because anxiety levels were expected to be higher in patients presenting with a ST-segmented elevation myocardial infarction (STEMI), STEMI-patients were excluded from the current study.

\section{Study design and treatments}

Patients were allocated to either a benzodiazepine (lorazepam, oxazepam, diazepam or midazolam) prior to their procedure or no premedication. The four benzodiazepines were all dosed at the minimal effective dose for adults, as is common practice in prophylactic settings (lorazepam $1 \mathrm{mg} / \mathrm{sl}$, oxazepam $10 \mathrm{mg} /$ po, diazepam $5 \mathrm{mg} /$ po, midazolam $7.5 \mathrm{mg} / \mathrm{po}$ ). Premedication was provided $30 \mathrm{~min}$ prior to the procedure. No other (intravenous) anxiolytic drugs were administered. The systematic allocation to one of the four benzodiazepines versus no premedication was organised in monthly rotational periods and as such simulating a randomised study. All patients who underwent CAG or PCI during a particular month of the study received the same premedication or no premedication according to a predetermined schedule (figure 1). After 5 months, the five premedication strategies were repeated to exclude seasonal influences. This was an open-label observational study; clinicians were not blinded for the medication the participants received. In addition, patients were not informed regarding the type of premedication they received. Furthermore, because of ethical considerations, patients were allowed to refuse their allocated premedication. Likewise, clinicians were permitted to withhold the allocated premedication because of possible drug interactions or other clinical considerations. Similarly, in the non-premedication group, any requests from patients or clinicians for a benzodiazepine, were granted.

\section{Study procedures and end points}

Anxiety was measured using the one-item Visual Analogue Scale for Anxiety (VAS score), ${ }^{13-15}$ ranging from 0 (not anxious) to 10 (extremely anxious). Patients completed the VAS in the presence of nurses who were available to assist if necessary. Anxiety was assessed at four moments in time (figure 2).

1. Directly at hospital intake.

2. Directly preprocedure, in the catheterisation laboratory.

3. Directly postprocedure, in the catheterisation laboratory.

4. At discharge (several hours after procedure).

Baseline patient and procedural characteristics were collected in a dedicated electronic database. Moreover, the patient self-reported level of education was recorded and categorised into low (less than 10 years of education), intermediate (between 11 and 14 years of education) and high (more than 14 years of education).

\section{Outcomes}

Primary outcome

The primary outcome was the difference in anxiety reduction between patients with lorazepam, oxazepam, diazepam or midazolam compared with the no premedication control group. The anxiety reduction $(\triangle \mathrm{VAS})$ was defined as the absolute difference in VAS-score directly preprocedure to directly postprocedure (figure 2).

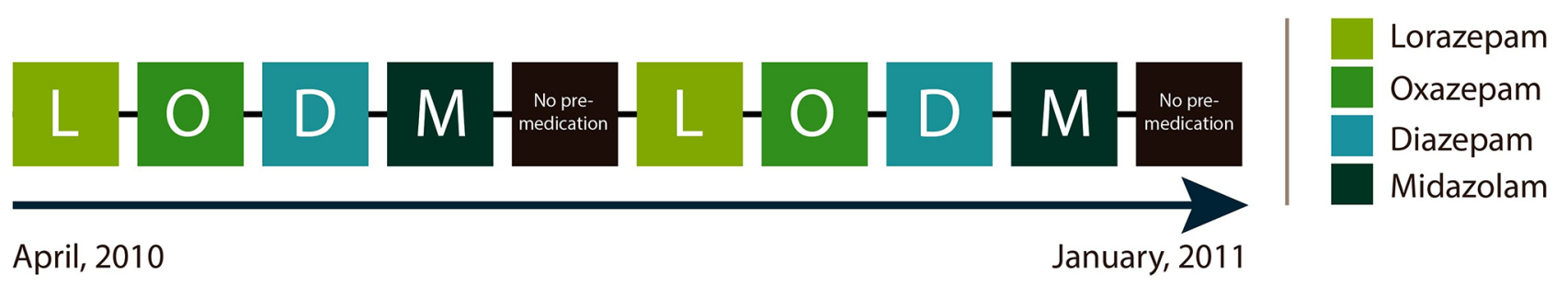

One block represents one month of study medication. In the fourth study month, 3 weeks of Midazolam were replaced with

no premedication due to the substantial amount of reported adverse drug effects.

Figure 1 Timeline allocation of premedication. 
Figure 2. Timeline measurement anxiety with VAS-score

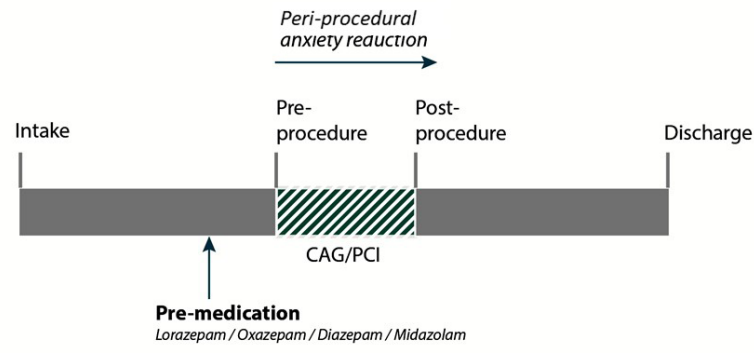

Figure 2 Timeline measurement anxiety with VAS score. CAG, coronary angiograms; $\mathrm{PCl}$, percutaneous coronary interventions; VAS, Visual Analogue Scale for Anxiety.

Anxiety reduction was selected to account for differences in baseline VAS-scores between patients. The moment preprocedure was chosen instead of the moment at hospital intake, since our earlier study showed anxiety scores peak directly before the start of the procedure. ${ }^{7}$

\section{Secondary outcomes}

Secondary outcomes were the absolute VAS scores per premedication strategy group and the no premedication group at the four different time points. Furthermore, all issues which could be directly attributed to the effect of benzodiazepines were prospectively noted by trained nurses and physicians as side effects.

\section{Statistical analysis}

There is a natural mean anxiety reduction of -1.8 in VAS score between pre and postprocedure in patients undergoing a CAG or PCI. ${ }^{7}$ Accordingly, an absolute difference of 0.5 point $(28 \%$ of the mean reduction in the earlier study) between the premedication and control group could reasonably account for a minimal clinical identifiable difference. Consequently, a sample size of 234 patients per premedication strategy group (1170 patients in total) was required to obtain a power of $95 \%$ chance of detecting, as significant at the $5 \%$ level, an increase in the primary outcome measure of 0.5 in the premedication group compared with the no premedication group. As described above, because of ethical responsibilities, patients were allowed to refuse their allocated premedication. Likewise, the urgent timeframe in primary procedures did not always allow time for premedication. Consequently, this superiority study was conducted with an as treated (per-protocol) analysis.

Values were tested for normality and appropriately reported as mean $\pm \mathrm{SD}$ for continuous variables or frequency for categorical variables. Paired t-tests were used to compute differences in anxiety scores over time. Independent t-tests were used to compute differences in anxiety reduction between the various premedication groups and the non-premedication group. All statistical tests were two-tailed, and a value of $\mathrm{p}<0.05$ was considered

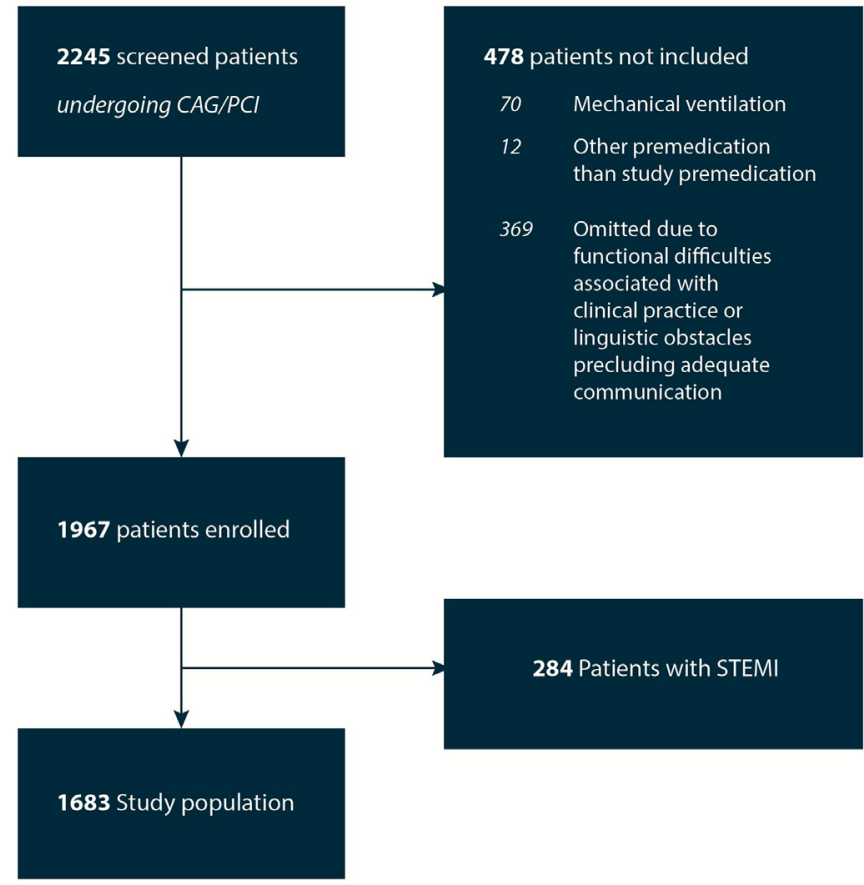

Figure 3 Flowchart patient enrolment and follow-up. CAG, coronary angiograms; $\mathrm{PCl}$, percutaneous coronary interventions; STEMI, ST-segmented elevation myocardial infarction.

statistically significant. Adverse side effects are presented both as an absolute number and as a percentage. Calculations were generated by SPSS software (V.21.0 for Windows, SPSS, Chicago, Illinois, USA).

\section{RESULTS}

\section{Enrolment and follow-up}

In total, 2447 patients underwent CAG or PCI during this 10 -month study period (figure 3 ). A total of 478 patients were not included due to functional difficulties associated with clinical practice, or obstacles precluding adequate communication such as language barriers and mechanical ventilation. Additionally, 284 patients presenting with STEMI were excluded. Consequently, a total of 1683 participants were included in the current study. Complete VAS scores were available in 1525 patients.

\section{Patient characteristics}

Table 1 shows the clinical baseline and procedural characteristics of the study population. The average age was $66 \pm 12$ years and the study population was predominantly male $(69 \%)$. The majority of the patients underwent PCI $(63 \%)$, which was commonly performed in an elective setting (97\%). Access site was either the radial $(52 \%)$ or the femoral artery $(48 \%)$. A substantial part of the patients $(40 \%)$ suffered a previous myocardial infarction. Similarly, a large part of the study population (48\%) had previously experienced a CAG or PCI. Patient and procedural characteristics were comparable among all four premedication groups and the control group. Unexpectedly, numerous patients experienced side effects during the first weeks of 
Table 1 Demographical and clinical characteristics

\begin{tabular}{|c|c|c|c|c|c|c|}
\hline & & & Lorazepam & Oxazepam & Diazepam & Midazolam \\
\hline Dose & & & $1 \mathrm{mg} / \mathrm{sl}$ & $10 \mathrm{mg} / \mathrm{os}$ & $5 \mathrm{mg} / \mathrm{os}$ & $7.5 \mathrm{mg} / \mathrm{os}$ \\
\hline Tmax & & & 2 hours & 2-3 hours & $1 / 2-11 / 2$ hour & $1 / 2-11 / 2$ hour \\
\hline$T 1 / 2$ & All & premedication & 12-16 hours & 4-15 hours & 20-48 hours & 2-31/2 hours \\
\hline Demographics & $n=1683$ & $n=526$ & $n=361$ & $\mathrm{n}=294$ & $n=327$ & $n=174$ \\
\hline Age (years) & $66 \pm 12$ & $66 \pm 11$ & $65 \pm 11$ & $66 \pm 12$ & $66 \pm 12$ & $63 \pm 11$ \\
\hline Male gender & $1159(69 \%)$ & $371(71 \%)$ & $248(69 \%)$ & $199(68 \%)$ & $219(67 \%)$ & $121(70 \%)$ \\
\hline BMI & $27 \pm 4$ & $28 \pm 4$ & $27 \pm 4$ & $27 \pm 4$ & $27 \pm 4$ & $27 \pm 4$ \\
\hline \multicolumn{7}{|l|}{ Level of education } \\
\hline Low & $379(23 \%)$ & $119(23 \%)$ & $90(25 \%)$ & $56(19 \%)$ & $73(22 \%)$ & $41(23 \%)$ \\
\hline Intermediate & $753(45 \%)$ & $230(44 \%)$ & $158(44 \%)$ & $139(47 \%)$ & $156(48 \%)$ & $70(40 \%)$ \\
\hline High & $350(21 \%)$ & $110(21 \%)$ & $79(22 \%)$ & $62(24 \%)$ & $60(18 \%)$ & $39(22 \%)$ \\
\hline Unknown & $201(12 \%)$ & $67(12 \%)$ & $34(9 \%)$ & $37(13 \%)$ & $38(12 \%)$ & $24(14 \%)$ \\
\hline \multicolumn{7}{|l|}{ Medical history } \\
\hline Myocardial infarction & $475(40 \%)$ & $166(43 \%)$ & $92(38 \%)$ & $80(39 \%)$ & $80(36 \%)$ & $57(42 \%)$ \\
\hline CAG or PCl & $604(48 \%)$ & $195(49 \%)$ & $115(44 \%)$ & $105(47 \%)$ & $120(51 \%)$ & $69(49 \%)$ \\
\hline \multicolumn{7}{|l|}{ Risk factors } \\
\hline Diabetes mellitus & $354(22 \%)$ & $129(26 \%)$ & $73(21 \%)$ & $46(16 \%)$ & $69(22 \%)$ & $37(22 \%)$ \\
\hline Known hypertension & $860(53 \%)$ & $275(55 \%)$ & $184(52 \%)$ & $153(53 \%)$ & $157(49 \%)$ & $91(54 \%)$ \\
\hline Family history of $\mathrm{CHD}$ & $1045(64 \%)$ & $318(64 \%)$ & $230(65 \%)$ & $179(62 \%)$ & $199(62 \%)$ & $119(70 \%)$ \\
\hline Hypercholesterolemia & $718(44 \%)$ & $226(45 \%)$ & $165(46 \%)$ & $105(36 \%)$ & $125(39 \%)$ & $97(57 \%)$ \\
\hline Current cigarette smoking & $301(18 \%)$ & $93(18 \%)$ & $65(18 \%)$ & $53(18 \%)$ & $57(17 \%)$ & $33(19 \%)$ \\
\hline \multicolumn{7}{|l|}{ Urgency and treatment } \\
\hline Elective CAG or PCl & $1625(97 \%)$ & $501(95 \%)$ & $346(96 \%)$ & $285(97 \%)$ & $321(98 \%)$ & $171(98 \%)$ \\
\hline Femoral artery approach & $796(48 \%)$ & $225(44 \%)$ & $179(50 \%)$ & $149(52 \%)$ & $161(50 \%)$ & $82(48 \%)$ \\
\hline CAG & $628(37 \%)$ & $202(38 \%)$ & $128(36 \%)$ & $107(36 \%)$ & $135(41 \%)$ & $56(32 \%)$ \\
\hline $\mathrm{PCl}$ & $1055(63 \%)$ & $324(62 \%)$ & $233(65 \%)$ & $187(64 \%)$ & $192(59 \%)$ & $118(68 \%)$ \\
\hline Number of grafts & $1.2 \pm 1.0$ & $1.2 \pm 1.0$ & $1.2 \pm 0.8$ & $1.2 \pm 1.0$ & $1.0 \pm 0.8$ & $1.3 \pm 0.9$ \\
\hline Procedure time (minutes) & $45 \pm 25$ & $45 \pm 24$ & $44 \pm 27$ & $46 \pm 26$ & $44 \pm 26$ & $43 \pm 22$ \\
\hline \multicolumn{7}{|l|}{ Follow-up } \\
\hline 1 years mortality & $58(4 \%)$ & $23(5 \%)$ & $11(3 \%)$ & $10(4 \%)$ & $10(3 \%)$ & $4(3 \%)$ \\
\hline 5 years mortality & $191(14 \%)$ & $70(16 \%)$ & 33 (11\%) & $41(17 \%)$ & 34 (13\%) & $12(8 \%)$ \\
\hline
\end{tabular}

Data are expressed as number (\%), mean \pm SD.

$\mathrm{BMI}$, body mass index; CAG, coronary angiography; CHD, coronary heart disease; PCI, percutaneous coronary interventions.

the midazolam 'month'. Subsequently, patients allocated to midazolam were converted to no premedication (figure 1). Consequently, the patient groups were not comparable in size, with the no premedication group as the largest $(\mathrm{n}=526)$, followed by lorazepam $(n=361)$, diazepam $(n=327)$, oxazepam $(n=294)$ and midazolam $(n=174)$. Patients did not refuse the allocated premedication. Only five patients were transferred to the no premedication group by their responsible clinicians (due to clinical reasons). In 44 patients allocated to no premedication, premedication was given on request by the patient or physician.

\section{Outcomes}

Primary outcome

Anxiety reduction significantly improved in patients who received benzodiazepines as premedication $(\triangle \mathrm{VAS}=-1.9$ \pm 2.9) compared with patients who did not receive premedication $(\triangle \mathrm{VAS}=-1.4 \pm 2.5, \mathrm{p}=0.004)$ (figure 4$)$. The use of diazepam generated the highest anxiety reduction $(\triangle \mathrm{VAS}=-2.0 \pm 2.6, \mathrm{p}=0.003)$, followed by lorazepam $(\triangle \mathrm{VAS}=-2.0 \pm 2.9, \mathrm{p}=0.007)$. The use of midazolam $(\triangle \mathrm{VAS}=-1.9 \pm 3.3, \mathrm{p}=0.13)$ or oxazepam $(\triangle \mathrm{VAS}=-1.6 \pm$ $2.8, \mathrm{p}=0.54$ ) did not lead to a significant anxiety reduction compared with no premedication (figure 5, table 2 ).

\section{Secondary outcomes}

During arrival in the catheterisation laboratory department, the mean VAS anxiety score for all patients was $4.0 \pm 2.7$. Anxiety levels slightly rose immediately before the starting of the procedure $(4.2 \pm 2.7, \mathrm{p}=0.024)$ and significantly declined postprocedure $(2.5 \pm 2.4, \mathrm{p}<0.001)$. The VAS anxiety score further declined at hospital discharge 


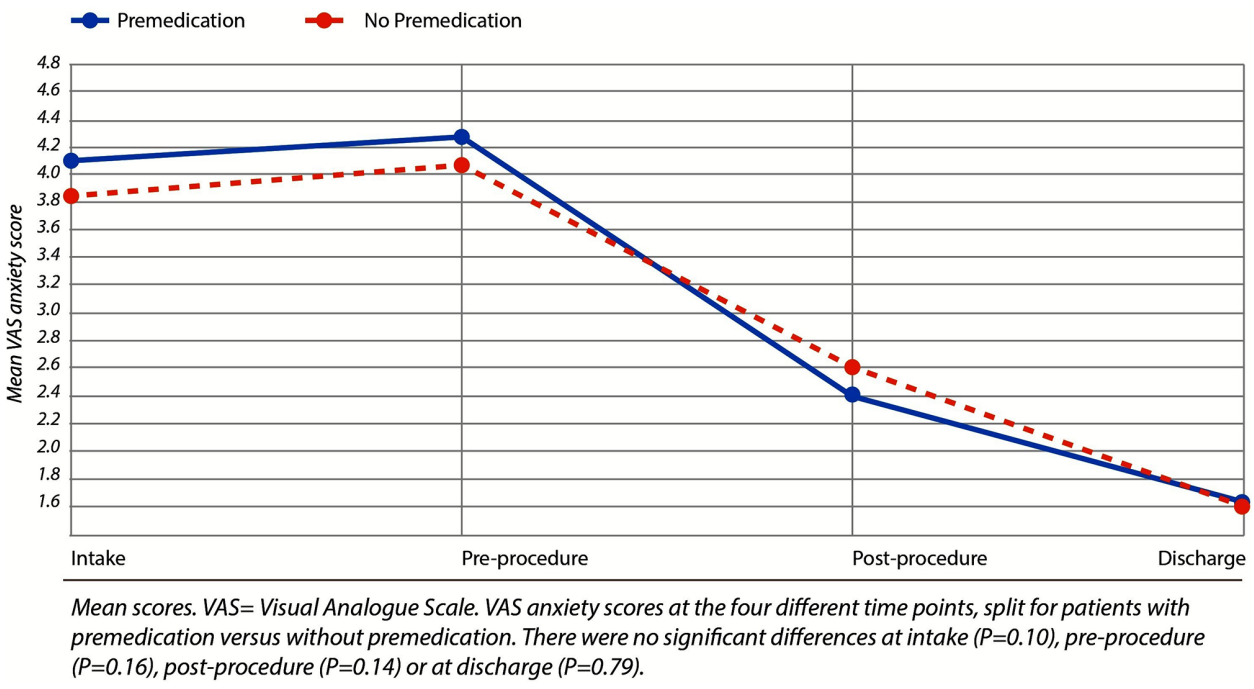

Figure 4 Visual Analogue Scale anxiety score premedication versus no premedication.

$(1.6 \pm 1.9, \mathrm{p}<0.001)$. Table 2 shows the course of the anxiety scores split for the different premedication schemes.

\section{Adverse drug effects}

Adverse drug effects were uncommon in participants premedicated with diazepam $(1.5 \%)$, lorazepam $(0.2 \%)$ and oxazepam $(0.3 \%)$ (figure 6$)$. In contrast, a substantial amount of the participants premedicated with midazolam $(n=39,19.8 \%)$ experienced one or more side effects . Several patients $(n=13)$ showed multiple drug effects. The majority $(n=36)$ of side effects in patients premedicated with midazolam consisted of drowsiness varying from sleepiness to profound unconsciousness. In addition, seven patients developed low peripheral capillary oxygen saturation. Occasionally, this recovered after simple stimulation but more frequently these patients required oxygen therapy. Moreover, a total of nine patients showed signs of physical agitation, and in several patients, these uncontrolled movements strongly hampered the procedure. In four patients, the responsible clinician administered flumazenil to counteract the effect of midazolam due to the severity of the side effects. Any reported side effects in the other medication groups consisted of mild complains of drowsiness.

\section{DISCUSSION}

In the current study with patients undergoing a CAG or PCI, premedication with either lorazepam $1 \mathrm{mg} / \mathrm{sl}$ or diazepam $5 \mathrm{mg} /$ po was an effective therapy to reduce preprocedural

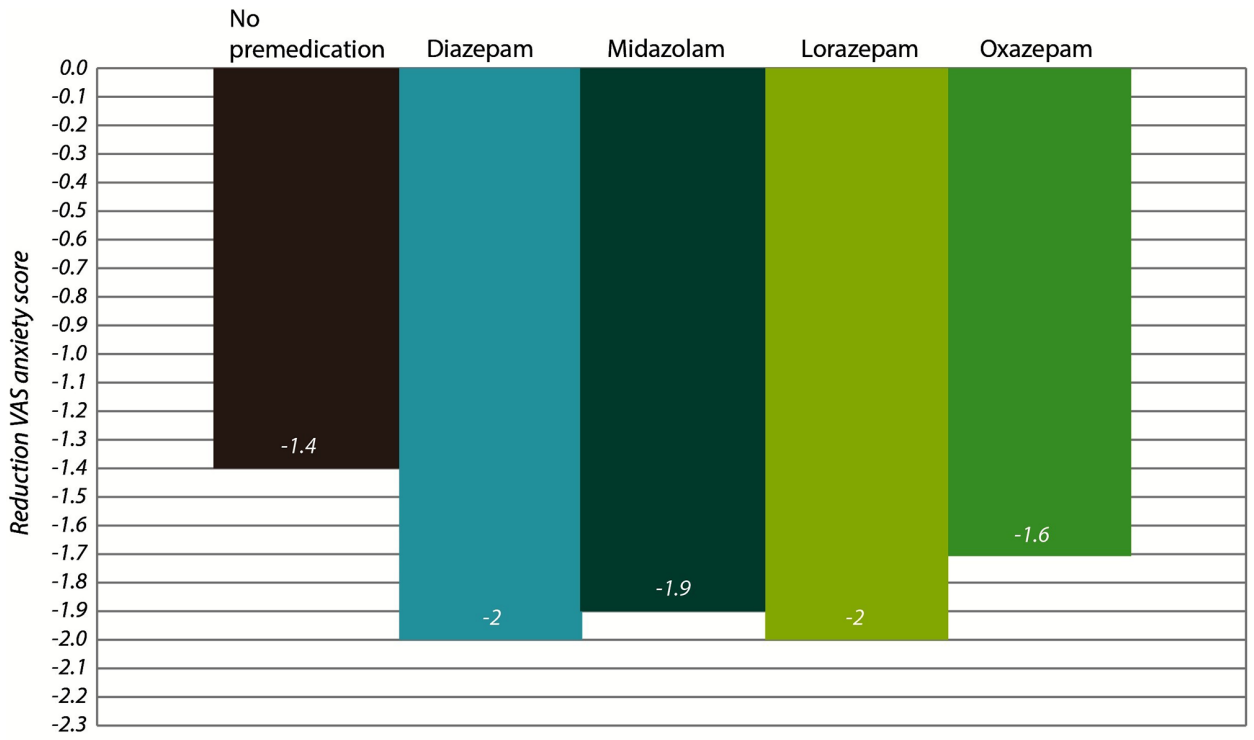

Mean reduction of VAS scores in patients split for the use of premedication. Reduction of anxiety is measured as the absolute reduction of VAS score post-procedure compared to pre-procedure. Premedication with Diazepam $(P=0.003)$ or Lorazepam $(P=0.007)$ resulted in significant anxiety reduction compared to no premedication.

Figure 5 Reduction in VAS scores split for different premedication. VAS, Visual Analogue Scale for Anxiety. 
Table 2 Prevalence of anxiety in patients split for different premedication groups

\begin{tabular}{|c|c|c|c|c|c|c|c|c|c|c|}
\hline & & & Diazepam & $\begin{array}{l}\mathbf{P} \\
\text { values* }\end{array}$ & Midazolam & P values* & Lorazepam & P values* & Oxazepam & $P$ values* \\
\hline Dose & & & $5 \mathrm{mg} / \mathrm{os}$ & & $7.5 \mathrm{mg} / \mathrm{os}$ & & $1 \mathrm{mg} / \mathrm{sl}$ & & $10 \mathrm{mg} / \mathrm{os}$ & \\
\hline Tmax & & & $1 / 2-11 / 2$ hou & & $1 / 2-11 / 2$ hour & & 2 hour & & 2-3 hours & \\
\hline$T^{1 / 2}$ & All & premedication & $20-48$ hour & & $2-31 / 2$ hours & & 12-16 hours & & 4-15 hours & \\
\hline VAS intake & $4.0 \pm 2.7$ & $3.9 \pm 2.6$ & $4.1 \pm 2.6$ & 0.34 & $4.2 \pm 2.8$ & 0.25 & $4.3 \pm 2.7$ & 0.05 & $4.0 \pm 2.7$ & 0.61 \\
\hline $\begin{array}{l}\text { VAS } \\
\text { preprocedure }\end{array}$ & $4.2 \pm 2.7$ & $4.1 \pm 2.6$ & $4.2 \pm 2.6$ & 0.05 & $4.4 \pm 2.8$ & 0.25 & $4.5 \pm 2.7$ & 0.03 & $4.0 \pm 2.8$ & 0.88 \\
\hline $\begin{array}{l}\text { VAS } \\
\text { postprocedure }\end{array}$ & $2.5 \pm 2.4$ & $2.6 \pm 2.4$ & $2.2 \pm 2.3$ & 0.03 & $2.4 \pm 2.7$ & 0.48 & $2.5 \pm 2.3$ & 0.45 & $2.5 \pm 2.5$ & 0.65 \\
\hline $\begin{array}{l}\text { VAS at } \\
\text { discharge }\end{array}$ & $1.6 \pm 1.9$ & $1.6 \pm 1.8$ & $1.5 \pm 1.8$ & 0.71 & $1.4 \pm 1.9$ & 0.37 & $2.0 \pm 2.1$ & 0.01 & $1.4 \pm 1.7$ & 0.17 \\
\hline
\end{tabular}

Data are mean \pm SD. VAS anxiety scores of patients undergoing CAG or $\mathrm{PCl}(n=1683)$ at the four different time points split for the different premedication schemes no premedication $(n=526)$, diazepam $(n=361)$, midazolam $(n=174)$, lorazepam $(n=361)$ and oxazepam $(n=294)$. ${ }^{*} \mathrm{P}$ values of VAS anxiety scores in patients with premedication compared with patients without premedication.

CAG, coronary angiograms; $\mathrm{PCl}$, percutaneous coronary interventions;VAS, Visual Analogue Scale.

anxiety. In contrast, the use of oxazepam $10 \mathrm{mg}$ po or midazolam $7.5 \mathrm{mg} /$ po did not lead to a significant anxiety reduction compared with patients who did not receive premedication. In addition, a high number of patients treated with midazolam developed side effects. High levels of anxiety in patients with $\mathrm{CAD}$ are associated with a lowered immune response and also alterations of cardiovascular function such as impaired heart rate variety, reduced vagal control, endothelial dysfunction and vascular inflammation. ${ }^{16-20}$ Moreover, high levels of anxiety in patients with CAD are associated with worse clinical outcomes such as poor physical function, a decrease in quality of life, recurrence of myocardial infarction, death and a higher healthcare consumption during many months after the acute phase. ${ }^{21-27}$ Therefore, strategies aiming to minimise anxiety in patients undergoing CAG and PCI are important for patient comfort and could potentially improve clinical outcomes and reduce healthcare costs.

\section{Comparison with the literature}

Despite the common use of benzodiazepines as premedication in the setting of CAG and PCI, this is to our knowledge the first large study comparing their effects on anxiety. In the study by Woodhead et $a l^{5}, \quad(\mathrm{n}=144)$ the incidence of access site related complications as haematomas, pseudoaneurysmas and arterial bleedings was equal in patients premedicated with diazepam or without premedication. Anxiety was stated to be equal in all groups. Nevertheless, this was measured with a single question that did not quantify anxiety levels. Second, a study by Bergeron $e t a l^{9}(\mathrm{n}=62)$

Figure 6. Incidence of adverse drug effects split for different premedication

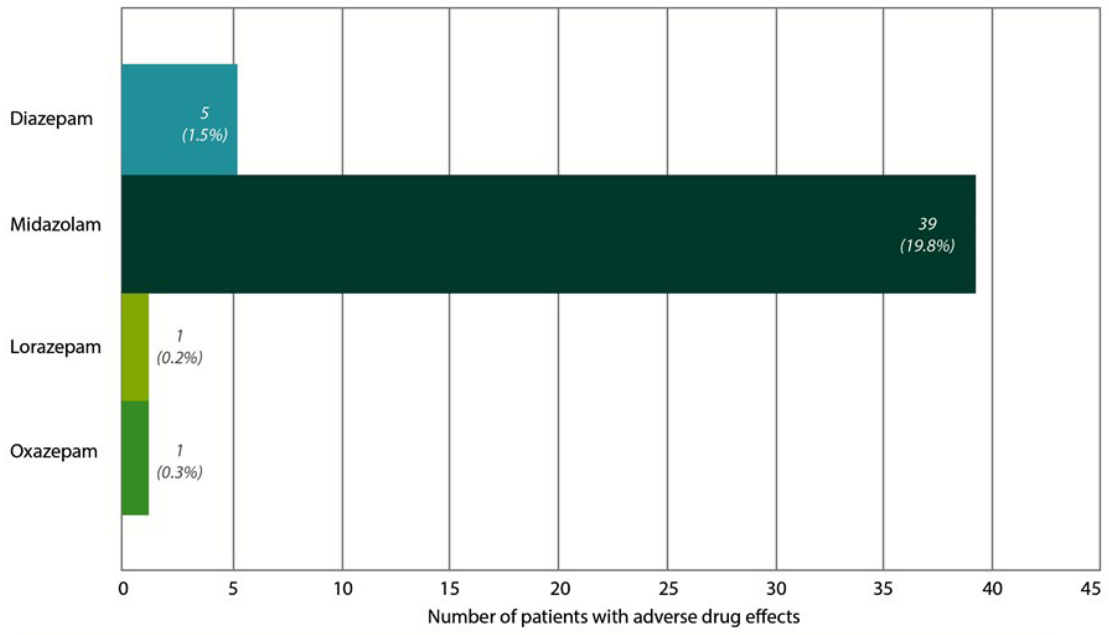

Adverse drug effects (ADE) are undesirable effects, reasonably associated with the pharmalogical action of the study medication. Numbers and percentages of patients with adverse drug affects are shown split for the different types of premedication

Figure 6 Incidence of adverse drug effects split for different premedication. 
used the VAS score at two points in time to assess anxiety in patients premedicated with lorazepam and diazepam but did not compare these results to a control group. Third, Kazemisaeid et al $(\mathrm{n}=151)$ conducted a placebo controlled double blind randomised controlled trial, which showed a significant increase in anxiety reduction (measured in VAS score) in patients premedicated with intravenous midazolam compared with both diazepam with intramuscular promethazine and a placebo. However, this could possibly be attributed to the fact that patients with higher preprocedural anxiety were premedicated with midazolam, rather than the anxiolytic effect of midazolam itself. Contrary to our current study, the postprocedural anxiety levels of their study did not differ among the diverse groups. Additionally, in contrast to our study, they did not report an increase of side effects in patients premedicated with midazolam. When summarising the previous reports, one may conclude that these earlier studies consisted of relatively small study populations, anxiety was not the primary outcome, anxiety was not always measured with a validated measuring method and there was not always a control group. Furthermore, in a single study, the use of benzodiazepines was associated with a higher risk on clopidogrel resistance (OR $5.8,95 \%$ CI 2.5 to $7.1, \mathrm{p}=0.03$ ). This potential effect would be undesirable in patients undergoing PCI. Nevertheless, we hypothesise that clopidogrel resistance is more likely to occur in frequent benzodiazepine users rather than in those with incidental use. ${ }^{28}$

Earlier studies reported beneficial effects of non-pharmacological interventions to reduce periprocedural anxiety. In three small randomised controlled trials, beneficial effects were seen on periprocedural self-reported anxiety in patients who received massage and/or guided imagery prior to the procedure. ${ }^{29-31}$ Similarly, a compilation of relaxing music during CAG or PCI provided by an audiopillow was associated with lower anxiety levels in the time period around the procedure. ${ }^{32}$ Finally, two small studies showed possible positive effects of aromatherapy as well as mindfulness-based interventions on anxiety. ${ }^{33}{ }^{34}$ We did not study these effects, and it is difficult to compare these effects with premedication strategies.

\section{Study limitations}

The intervention was not placebo controlled and blinded to neither clinicians nor patients. Additionally, group sizes were unequal, the result of midazolam being replaced with the administration of no premedication. Consequently, the group of patients premedicated with midazolam was underpowered to reach significance, despite absolute anxiety reduction scores comparable to lorazepam and diazepam. Moreover, all premedication was administered to participants $30 \mathrm{~min}$ before procedure even though the time to reach peak plasma concentration of the drug after administration (Tmax) for two of the used benzodiazepines might be at the end or even after the procedure. If administered earlier, lorazepam ( $\operatorname{Tmax}=2$ hours) and oxazepam ( Tmax $=2-3$ hours) might have had a different impact on measured anxiety levels. However, the strategy of $30 \mathrm{~min}$ before the procedure, in our opinion, does reflect current daily practice. Finally, despite significant differences in anxiety reduction between patients with and without premedication, the actual effect size in anxiety is small. In patients without premedication, there is a $36 \%$ reduction of preprocedural anxiety after the procedure, compared with $44 \%$ in patients premedicated with lorazepam and $48 \%$ with diazepam. Moreover, patients with lorazepam had significantly higher anxiety scores at discharge compared with patients without premedication. Accordingly, lorazepam's effect on anxiety and patient wellbeing after discharge remains questionable. Consequently, the clinical relevance remains undetermined and further studies are necessary to confirm potential benefits from premedication.

\section{CONCLUSION}

In this first study systematically examining the effects of premedication in patients undergoing CAG or PCI, the use of lorazepam $1 \mathrm{mg} / \mathrm{sl}$ or diazepam $5 \mathrm{mg} /$ os was associated with a significant but modest reduction in anxiety compared with no premedication. Oxazepam $10 \mathrm{mg} / \mathrm{po}$ and midazolam $7.5 \mathrm{mg} /$ po did not significantly reduce anxiety.

\section{Impact on daily practice}

The standard administration of lorazepam or diazepam before CAG or PCI provides patients with a modest reduction of periprocedural anxiety. However, costs are low and side effects are negligible. Therefore, in our opinion, standard prophylactic use seems fair. Routinely, administration of oxazepam or midazolam has a limited effect on the reduction of anxiety. Additionally, premedication of midazolam is associated to a high incidence of adverse effects. Therefore, this study does not support the routine use of oxazepam or midazolam as premedication to reduce anxiety.

Acknowledgements We would like to acknowledge and thank all patients, interventional cardiologists and catheterisation laboratory nurses for contributing to the current trial.

Contributors WV and RD were responsible for the writing of the current manuscript. WJR, TCW, AH, MGM, MMV, JJW, KTK, RJdW, JB, MAGS, JJP and JPSH all helped to collect data and provided valuable edits to the manuscript.

Funding This study was initiated and sponsored by the Heart Center of the Academic Medical Center.

Competing interests None declared.

Patient consent Not required.

Ethics approval Institutional Review Board of the Academic Medical Center (AMC). Provenance and peer review Not commissioned; externally peer reviewed. Data statement No additional data are available.

Open access This is an open access article distributed in accordance with the Creative Commons Attribution Non Commercial (CC BY-NC 4.0) license, which permits others to distribute, remix, adapt, build upon this work non-commercially, and license their derivative works on different terms, provided the original work is properly cited, appropriate credit is given, any changes made indicated, and the use is non-commercial. See: http://creativecommons.org/licenses/by-nc/4.0/ 


\section{REFERENCES}

1. Grace SL, Abbey SE, Irvine J, et al. Prospective examination of anxiety persistence and its relationship to cardiac symptoms and recurrent cardiac events. Psychother Psychosom 2004;73:344-52.

2. Astin F, Jones K, Thompson DR. Prevalence and patterns of anxiety and depression in patients undergoing elective percutaneous transluminal coronary angioplasty. Heart Lung 2005;34:393-401.

3. Edéll-Gustafsson UM, Hetta JE. Fragmented sleep and tiredness in males and females one year after percutaneous transluminal coronary angioplasty (PTCA). J Adv Nurs 2001;34:203-11.

4. Lenzen MJ, Gamel CJ, Immink AW. Anxiety and well-being in firsttime coronary angioplasty patients and repeaters. Eur J Cardiovasc Nurs 2002;1:195-201.

5. Woodhead J, Harding SA, Simmonds M, et al. Premedication for cardiac catheterization and percutaneous coronary intervention: does it increase vascular access site complications? J Cardiovasc Nurs 2007;22:466-71.

6. Trotter R, Gallagher R, Donoghue J. Anxiety in patients undergoing percutaneous coronary interventions. Heart Lung 2011;40:185-92.

7. Delewi R, Vlastra W, Rohling WJ, et al. Anxiety levels of patients undergoing coronary procedures in the catheterization laboratory. Int J Cardiol 2017;228:926-30.

8. Kazemisaeid A, Zeinali AH, Davoodi G, et al. Premedication for coronary angiography: effects on anxiety and hemodynamic status. Indian Heart J 2007;59:454-8.

9. Bergeron, Enns D. Effects of routine premedication for cardiac catherization on sedation, level of anxiety and arterial oxygen saturation. Can J Cardiol 1995;11:5.

10. Mullins. Cardiac catherization in congenital heart disease. New Jersey: Wiley, 2006.

11. Mukherjee B. Cardiovascular catherization and intervention. Florida: CRC Press, 2010.

12. British Medical Association. British national formulary. London: British Medical Association, 2009.

13. Facco E, Zanette G, Favero L, et al. Toward the validation of visual analogue scale for anxiety. Anesth Prog 2011;58:8-13.

14. Facco E, Stellini E, Bacci C. Validation of visual analogue scale for anxiety (VAS-A) in preanesthesia evaluation. Minerva Anestesiologica 2013;79:7.

15. Rossi V, Pourtois G. Transient state-dependent fluctuations in anxiety measured using STAI, POMS, PANAS or VAS: a comparative review. Anxiety Stress Coping 2012;25:603-45.

16. Fehder WP. Alterations in immune response associated with anxiety in surgical patients. CRNA 1999;10:124-9.

17. Martens EJ, Nyklícek I, Szabó BM, et al. Depression and anxiety as predictors of heart rate variability after myocardial infarction. Psychol Med 2008;38:375-83.

18. Munk PS, Isaksen K, Brønnick K, et al. Symptoms of anxiety and depression after percutaneous coronary intervention are associated with decreased heart rate variability, impaired endothelial function and increased inflammation. Int $\mathrm{J}$ Cardiol 2012;158:173-6.
19. Watkins LL, Blumenthal JA, Carney RM. Association of anxiety with reduced baroreflex cardiac control in patients after acute myocardial infarction. Am Heart J 2002;143:460-6.

20. Spalding TW, Jeffers LS, Porges SW, et al. Vagal and cardiac reactivity to psychological stressors in trained and untrained men. Med Sci Sports Exerc 2000;32:581-91:581-91.

21. Huffman JC, Smith FA, Blais MA, et al. Anxiety, independent of depressive symptoms, is associated with in-hospital cardiac complications after acute myocardial infarction. J Psychosom Res 2008;65:557-63.

22. Park JH, Tahk SJ, Bae SH. Depression and anxiety as predictors of recurrent cardiac events 12 months after percutaneous coronary interventions. J Cardiovasc Nurs 2015;30:351-9.

23. Shibeshi WA, Young-Xu Y, Blatt CM. Anxiety worsens prognosis in patients with coronary artery disease. J Am Coll Cardiol 2007;49:2021-7.

24. Strik JJ, Denollet J, Lousberg R, et al. Comparing symptoms of depression and anxiety as predictors of cardiac events and increased health care consumption after myocardial infarction. J Am Coll Cardiol 2003;42:1801-7.

25. Wang G, Cui J, Wang Y, et al. Anxiety and adverse coronary artery disease outcomes in Chinese patients. Psychosom Med 2013;75:530-6.

26. Lane D, Carroll D, Ring C, et al. Mortality and quality of life 12 months after myocardial infarction: effects of depression and anxiety. Psychosom Med 2001;63:221-30.

27. Sullivan MD, LaCroix AZ, Baum C, et al. Functional status in coronary artery disease: a one-year prospective study of the role of anxiety and depression. Am J Med 1997;103:348-56.

28. Feher G, Koltai K, Alkonyi B, et al. Clopidogrel resistance: role of body mass and concomitant medications. Int J Cardiol 2007;120:188-92.

29. Armstrong K, Dixon S, May S, et al. Anxiety reduction in patients undergoing cardiac catheterization following massage and guided imagery. Complement Ther Clin Pract 2014;20:334-8.

30. Ruffinengo C, Versino E, Renga G. Effectiveness of an informative video on reducing anxiety levels in patients undergoing elective coronarography: an RCT. Eur J Cardiovasc Nurs 2009;8:57-61.

31. Peng S, Ying B, Chen $Y$, et al. Effects of massage on the anxiety of patients receiving percutaneous coronary intervention. Psychiatr Danub 2015;27:44-9.

32. Weeks BP, Nilsson U. Music interventions in patients during coronary angiographic procedures: a randomized controlled study of the effect on patients' anxiety and well-being. Eur $J$ Cardiovasc Nurs 2011;10:88-93

33. Cho MY, Min ES, Hur MH, et al. Effects of aromatherapy on the anxiety, vital signs, and sleep quality of percutaneous coronary intervention patients in intensive care units. Evid Based Complement Alternat Med 2013;2013:1-6.

34. Nyklíček I, Dijksman SC, Lenders PJ, et al. A brief mindfulness based intervention for increase in emotional well-being and quality of life in percutaneous coronary intervention (PCl) patients: the MindfulHeart randomized controlled trial. J Behav Med 2014;37:135-44. 